\title{
INMIGRACIÓN, COTIDIANIDAD Y CONFLICTO NACIONAL EN LA BIOGRAFÍA Y ARCHIVO DE MANUEL YANULAQUE SCORDA (INMIGRANTE GRIEGO EN ARICA 1850-1934)*
}

\author{
IMMIGRATION, EVERYDAY LIFE AND NATIONAL CONFLICT \\ THE BIOGRAPHY AND FILING OF MANUEL YANULAQUE SCORDA \\ (GREEK IMMIGRANT IN ARICA 1850-1934) \\ Rodrigo Ruz Zagal ${ }^{* *}$ y Alfonso Díaz Aguad ${ }^{* * *}$
}

\begin{abstract}
El presente artículo tiene por objetivo profundizar en la vida de Manuel Yanulaque Scorda, inmigrante griego llegado al sur peruano en 1874 y su proceso de integración a la sociedad ariqueña en un período complejo de su historia, como fue la Guerra del Pacífico y la situación posterior caracterizada por un conflicto diplomático, político, social y cultural (1880-1929). A partir de una mirada cualitativa a su archivo personal se evalúan los impactos en la vida del inmigrante griego de los diversos contextos y momentos que marcaron el tránsito entre el siglo XIX y el XX a escala regional.
\end{abstract}

Palabras claves: Inmigración, vida cotidiana, conflicto nacional.

This article aims to deepen the life of Manuel Yanulaque Scorda, Greek immigrant arrived in southern Peru in 1874 and the process of integration into society Arica in a complex period in its history, as was the Pacific War and its aftermath of diplomatic, political, social and cultural (1880-1929). From a qualitative look at your records, assesses impacts Greek immigrant life different contexts and moments that marked the transit between the nineteenth and twentieth regionally.

Key words: Inmigration, everyday life, national conflict.

\section{Introducción}

\section{Sujeto, archivo y biografía. Una mirada cualitativa}

La historia por naturaleza (sea esta por método o defecto epistemológico) requiere en sus momentos cruciales de cierta materialidad que conecte el pasado con el presente, y a partir de esta conexión desplegar esfuerzos para entender los hechos del ser humano. La ausencia de vestigios y materiales desencadenan desajustes normalmente evidenciables en silencios que vuelven difusos ciertos procesos y momentos del pasado.

Los historiadores saben de esto; no es casual que ante ciertos contextos la historia deje de fluir como narración ante la ausencia testimonial. En esto radica la importancia del acceso a fuentes de diversas cualidades y características ${ }^{1}$, ya que por razones esenciales e incluso éticas, su presencia obliga, incomoda y desafía a los analistas a hacerse cargo del pasado desde el presente.
Los historiadores del norte chileno enfrentan en su quehacer muchos de dichos silencios, algunos atribuibles a ausencias testimoniales y otros endosables a la falta de agudeza investigadora. La primera de estas razones, posee una complejidad mayor que va más allá de una cuestión de registro ${ }^{2}$, ya que el silencio también es resultado de la perplejidad perturbadora provocada por fenómenos traumáticos que han caracterizado el devenir histórico regional: guerras, posguerras, imposición de fronteras, migraciones forzadas, militarismo, violencia étnica y política, entre otras calamidades que han marcado con fuerza el carácter de la sociedad regional y fronteriza ${ }^{3}$.

La historia regional poco a poco ha desplegado esfuerzos para desarrollar abordajes que contengan una dimensión humana de estos procesos, comenzando con esto a desplazar el canon tradicional en donde el estatus del historiador exigía que este se hiciese cargo de macroprocesos políticos y económicos, relegando a la auxiliaridad la mirada humana y antropológica de la cuestión.

\footnotetext{
* Resultado del Proyecto FONDECYT No 110965 y Proyecto de Investigación UTA 5735-13. Agradecimientos al Convenio de Desempeño UTA-MINEDUC. Una versión preliminar con carácter de divulgación en Ruz y González (2013).

** Universidad de Tarapacá, Departamento de Ciencias Históricas y Geográficas, Arica, Chile. Correo electrónico: rruz@uta.cl *** Universidad de Tarapacá, Departamento de Ciencias Históricas y Geográficas, Arica, Chile. Correo electrónico: adiaz@ uta.cl
} 
El siglo XXI ha sido para el desarrollo historiográfico del norte chileno un momento pródigo en cuanto acentuar la importancia del sujeto en los procesos históricos, recogiendo con este impulso el guante respecto de lo que la historia ha denominado como el "giro antropológico" de esta. Vuelco necesario para atender y enfrentar los procesos sociales y culturales de la región en que habitamos; con este engarce, la historia regional se vincula con el desarrollo historiográfico mundial que desde mediados del siglo pasado propugnaba esta relación (Galdames 2013).

El año 2010 Ariela González Yanulaque nieta, del inmigrante griego Manuel Yanulaque Scorda (1850-1934, asentado en Arica desde 1874), quien durante toda su vida fuese custodia del importante archivo personal fotográfico, epistolar y de objetos personales legados por Manuel, realizó las gestiones para que este se sistematizara, conservara y difundiera a través de la gestión conjunta entre el Archivo Histórico Vicente Dagnino de la Universidad de Tarapacá y el linaje Yanulaque ${ }^{4}$. De esta manera los recuerdos personales y familiares que hasta el momento se mantenían lejos del interés intruso de terceros, pasaron a tener una exposición pública transformando sus imágenes en una composición que será "leída" por gran parte de la comunidad regional y nacional.

El archivo de Manuel Yanulaque Scorda posee una cualidad única, que es hacer visible la historia de un inmigrante europeo llegado a una sociedad regional multicultural, multiétnica y convulsionada hacia la segunda mitad del siglo XIX. El relato documental en su estado bruto entrega una composición que contiene elementos de la vida que pocas veces se hacen evidentes y que van desde su asentamiento en la ciudad de Arica, la nostalgia por el terruño dejado atrás, la formación de vínculos afectivos y amistades entrañables, el surgimiento del amor y la formación de una familia; pero también refleja los sinsabores de haberse visto inserto en procesos de la historia ariqueña de la cual no mucho se habla, como lo es la situación de y la postguerra del Pacífico, la convulsión y tensiones de un momento que sacó a relucir las peores características del ser humano, pero también hicieron despertar sentimientos positivos como la solidaridad, comprensión, compasión y empatía con quien sufre.

El despliegue de estrategias y métodos cualitativos orientados a aprehender cuestiones inefables de una experiencia de vida, se desarrolla en esta investigación a partir de la aplicación del método biográfico, el cual ocupa un sitial privilegiado en cuanto ahondar en las subjetividades del ser humano, pese a su incómoda atadura a lo que algunos detractores del género definen como historia-ficción, vocación novelesca o aspiración moralizante (Dosse 2007).

No obstante, en las últimas décadas estos estudios han sido resignificados y revalorizados mundialmente a partir del desarrollo de la vertiente francesa vinculada a la historia de las mentalidades (Dosse 2007), historia cultural anglosajona (Burke 2000, 2006; Serna y Pons 2005), así como de los enfoques microanalíticos y microhistóricos desarrollados también desde fines del siglo pasado por conocidos historiadores italianos y españoles (Serna y Pons 2000; Hernández 2004), siendo para la historia un aporte en cuanto otorga espesor a la superficialidad con que el registro histórico oficial aborda situaciones "poco relevantes" para una historia docta, abriendo los espacios y cobertura hacia temas y problemas nuevos, así como a códigos y rincones que por sus características no serían visibles por otras artes y técnicas investigativas; permitiendo a su vez, conectarse con el importante desarrollo de las metodologías cualitativas en boga a partir de las crisis paradigmáticas globales en Ciencias Sociales (Noiriel 1997; Hernández 2004) 5 .

Estos códigos normalmente se encuentran encriptados en soportes que, gracias a su escasa atención y subvaloración, guardan consigo importante información visible solo para quienes atienden y "ven" su valor. Así, la documentación que los estudios históricos tradicionales consideraban como fuentes de segundo orden en relación con la prioridad oficial, como por ejemplo diarios personales, colecciones epistolares, correspondencia, objetos personales, registros iconográficos (fotografía, películas, videos) han comenzado a ser valorados, poniendo, dicho sea de paso, desafíos para quienes emprenden su estudio en cuanto a la validez de su interpretación (Burke 2005).

A pesar de que esta emergencia haya sido asimilada y compartida por el gremio de historiadores y otros cientistas sociales, los estudios empíricos siguen siendo escasos en comparación a su notable desarrollo teórico y conceptual. Los estudios cualitativos que desarrollan seria y espesamente aspectos relativos a la subjetividad (como los afectos, sensibilidades, ideas o mentalidades) aún son subdesarrollados, o en su defecto, tratados 
de forma simple y ligera quedando normalmente en la consigna y discurso. He ahí la importancia de profundizar en dicha pobreza ${ }^{6}$.

\section{Manuel Yanulaque Scorda. Inmigrante griego en Arica}

\section{Arribo e integración en la comunidad local}

Manuel Yanulaque Scorda (1850), nativo de la isla de Paros en la cuenca del Mediterráneo europeo, hacia la segunda mitad del siglo XIX emprendió la aventura más grande de su vida al dejar el seno de su país para buscar horizontes en territorios desconocidos. Sin planes y sin contactos, suponemos que el viaje a Sudamérica calmó temporalmente el ímpetu aventurero del joven griego.

Existen algunos antecedentes familiares que lo ligan a un oficio inquieto; marinero. Mas no sabemos si fue su carácter $u$ otras razones, las que lo hicieron emigrar en soledad y no volver jamás a la tierra de sus origenes. Manuel Yanulaque, a pesar de añorar entrañablemente la Grecia natal, nunca retornó a ella.

No hay certeza respecto del año de inicio de su aventura sudamericana, aunque datos censales de $1924^{7}$ indican que Manuel al momento de ser encuestado declaró 50 años de residencia en Arica, por lo que su arribo debió ser el año 1874, contando en ese momento con 24 años de edad ${ }^{8}$.

Arica en el momento de su llegada pertenecía administrativamente al Departamento de Arequipa, Provincia de Arica (Díaz et. al. 2008 y 2010). La ciudad, que seguramente manifestaba la calma propia que aún es posible de palpar, estaba compuesta por una población citadina escasa en comparación a la abundancia poblacional valluna, serrana y altiplánica (Ruz et. al. 2008) ${ }^{9}$, donde el espacio urbano poseía un carácter cosmopolita (Galdames et. al. 2008) ${ }^{10}$.

Sostenida económicamente por su actividad portuaria y aduanera, la ciudad mantenía el estatus adquirido desde tiempos de la colonia española y momentos prehispánicos, de ser el punto nodal de articulación en el área centro surandina.

Al momento de arribo de Manuel, Arica era el punto costero de ingreso hacia las zonas interiores del sur peruano (Tacna-Puno) ejerciendo también de tradicional engarce con las alturas de Bolivia, el que se fortaleció y modernizó posteriormente con la construcción del ferrocarril Arica-La Paz (Díaz et. al. 2012).
Estas características hicieron que el bucólico Arica de antaño, a pesar de su carácter cansino, poseyera un frenético dinamismo portuario, ferroviario y comercial, por lo que su centro de actividades se concentraba en torno al puerto, bullante de servicios aduaneros, estiba portuaria, transporte de carga ferroviaria, tránsito de viajeros, siendo el borde costero el eje articulador de la ciudad en la vida urbana (Díaz et. al. 2012).

Quizás Manuel Yanulaque era un conocedor de la situación sudamericana, surperuana y ariqueña al momento de decidir embarcarse hacia los nuevos rumbos, o quizás solamente el azar sumado al ímpetu juvenil conjugó en su arribo. De cualquier forma, las características socioeconómicas de Arica entrada la segunda mitad del siglo XIX fueron el ambiente propicio para el desarrollo de las potencialidades de Manuel.

Tempranamente en Arica, Manuel establece vínculos con un importante personaje de ascendencia italiana en la ciudad, don Domingo Pescetto Ceppi (1836-1904), sujeto que representaba el arquetipo en cuanto al éxito de las empresas personales migratorias en el sur del Perú. Este italiano proveniente de Savona y llegado a Arica se transformó como muchos de su compatriotas en un próspero comerciante llegando con los años a posicionarse como el último alcalde de la administración peruana en los críticos momentos de la postguerra peruanochilena (1879-1883).

Su relación con Pescetto fue profunda, cómplice y fortalecida con el tiempo. Esta complicidad se refleja en el hecho de que haya sido Domingo quien presentó a Manuel a la mujer con quien compartiría su vida, María Esperanza Ayala Corvacho, fuerte mujer ariqueña nacida en 1848, componente de la poderosa familia Corvacho que la tradición y la historia reconoce como una de la más antiguas familias netamente ariqueñas y de estirpe afrodescendiente.

María y Manuel habrían comenzado su relación hacia 1879, considerando que en 1880 nace su hija primogénita, María. Ambos formalizarían el vínculo casándose en 1891, mientras que su casamentero Domingo Pescetto, también adquirió nupcias en 1881 con otra mujer afrodescendiente, la azapeña Melchora Cornejo Corvacho, prima de María Esperanza.

Este hecho ligó a ambos europeos con la tradición local, asumiendo parentesco sanguíneo y familiar con las principales castas de raza negra 
ariqueña, hecho no menor considerando que este atributo arraigó a ambos migrantes con el terruño y la cultura afroariqueña.

El vínculo entre Manuel y Domingo Pescetto posteriormente se afianzó cuando la primogénita de los Yanulaque-Ayala adquiriera nupcias con Pedro, Hijo de los Pescetto-Cornejo, situación que los emparentó.

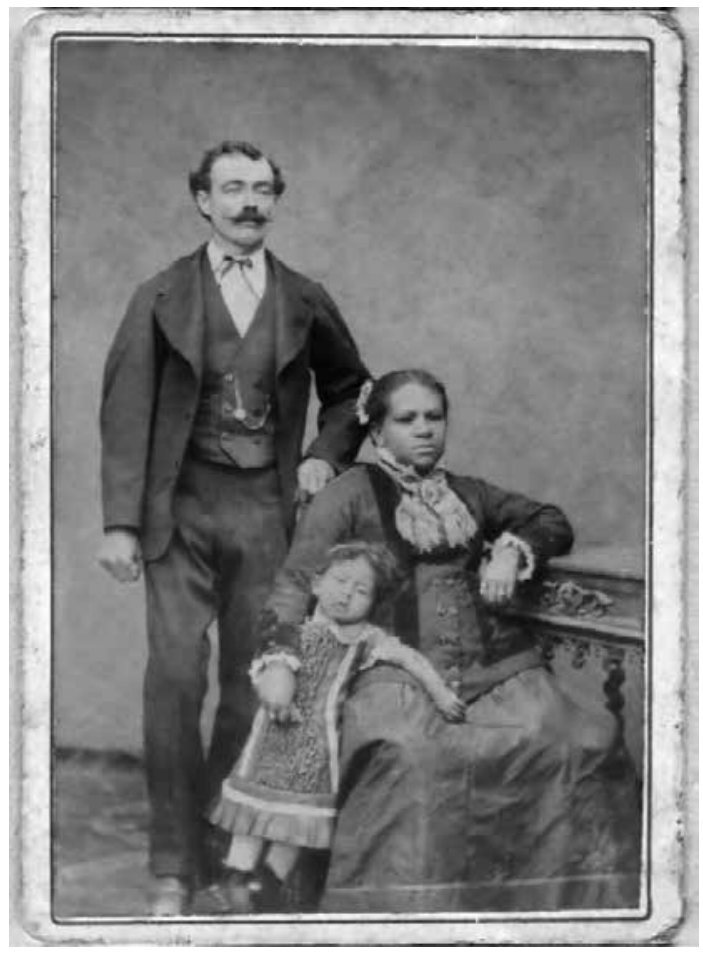

1885. La joven pareja conformada por Manuel y María Esperanza con su primogénita, María. FMYS609.

De la unión Yanulaque-Ayala nacieron 10 hijos: María (1880), Juan (1882), José (1884), Jorge (1885), Manuel (1887), Catalina (1889), Bárbara (1890), Juan $2^{\circ}$ (1893), Leónidas (1895) y Esperanza (1897). De estos, Manuel y María Esperanza sufrieron la pérdida temprana de Juan (fallecido a los 9 años) y Jorge a los robustos 20 años, sumiendo a la familia en una profunda tristeza.

La educación de su descendencia fue para el matrimonio la principal empresa donde concentraron sus esfuerzos, por esta razón todos sus hijos fueron enviados a realizar sus estudios a importantes colegios de la zona centroandina como el Colegio de Monjas Nuestra Señora del Rosario de Arequipa, Instituto Superior de la ciudad de Puno y a los colegios chilenos Colegio de Señoritas de la Inmaculada Concepción en Copiapó y el Colegio Mc Kay de Valparaíso.

Sin lugar a dudas que los desafíos del cambio de siglo fueron un factor importante para las decisiones del visionario Manuel, quien aventajado por su experiencia europea fue afincando la idea de desarrollar actividades en su vida que estuvieran al nivel y exigencias del tránsito de los tiempos.

Los comienzos de la vida de Manuel en el Perú de la segunda mitad del siglo XIX se habían dado en un contexto óptimo para la exitosa proliferación del comercio, rubro liderado por europeos, especialmente italianos, quienes desarrollaron importantes emprendimientos económicos en todo el sur peruano relacionados con el comercio mayorista y minorista, agencias aduaneras, especulación inmobiliaria y agricultura. Situación que posteriormente habría mejorado bajo el contexto posguerra del Pacífico considerando la supuesta imparcialidad europea frente al conflicto diplomático chileno-peruano que se extendió hasta 1929 (Díaz 2000 y 2002).

En este contexto Manuel se inició como hombre de negocios instalándose hacia 1890 con un pequeño despacho ubicado en la siempre denominada calle San Marcos esquina calle del Colegio (actual Colón). Posteriormente, contando con mayores recursos se traslada al Pasaje Chucuito (actual pasaje Sangra) esquina 28 de Julio (actual Sotomayor) donde se instala con un almacén más amplio cuyo segundo piso lo utilizó como casa habitación. Resultado de la prosperidad económica, compra y construye una segunda etapa del almacén que le permite ampliar el local, tener grandes bodegas y oficinas.

El almacén denominado "La Colmena" abasteció entre los años 1890 y 1980 a la comunidad ariqueña de abarrotes, licorería, ferretería, vidriería, géneros, loza, zapatería, moda europea, etc., aprovisionando en sus primeros años además de Arica a las ciudades de Tacna, Arequipa y La Paz.

Los años de bonanza económica cultivaron en Manuel el espíritu benefactor, manteniendo hasta su vejez los aportes económicos al Hospital San Juan de Dios y a las religiosas Hijas de Santa Ana que allí trabajaban, así como a la Primera Compañía de Bomberos Bernardo O'Higgins. Del mismo modo servía a eventuales compatriotas de paso o aventurados en Arica, como nexo con el Consulado de Grecia existente en Valparaíso. 


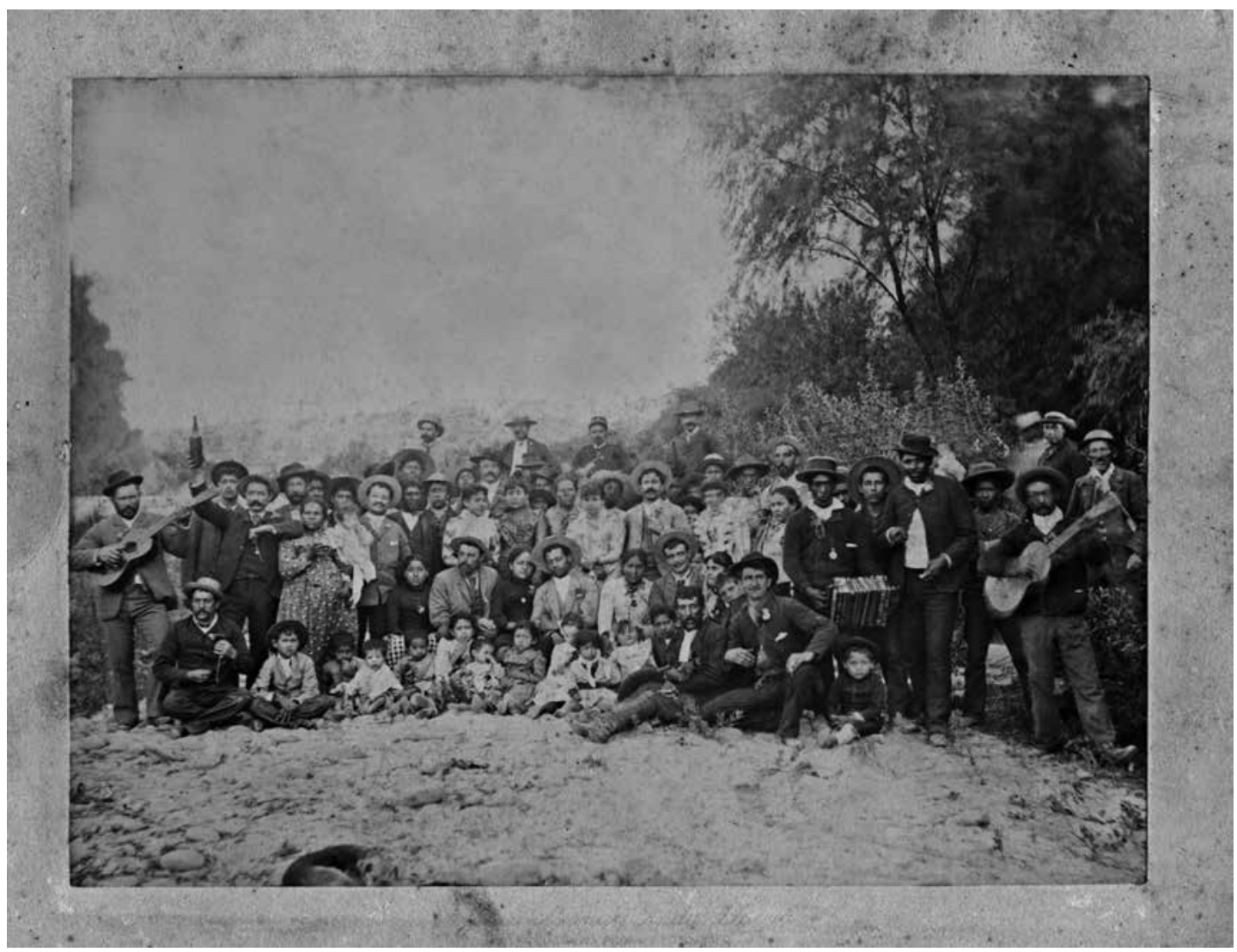

1891. Celebración del cumpleaños de María Esperanza en el sector de las Chimbas, espacio importante dentro de la cultura afroariqueña. FMYS382.

\section{Conflictos políticos y repercusiones en la vida de Manuel Yanulaque}

Si bien el siglo XIX se presentó a Manuel como el momento de desarrollarse económicamente, el cambio de siglo trajo consigo el hacer frente a la perturbadora realidad que cubrió y marcó literalmente a fuego la historia de Arica en dicho transitar. Manuel Yanulaque vivió la Guerra del Pacífico en el sangriento escenario local, siendo la tradición oral familiar la que nos señala que Manuel y María Esperanza embarazada tuvieron que huir de la asolada ciudad en los duros momentos de la Batalla de Arica, debiendo refugiarse como muchos ariqueños en la profundidad del valle de Azapa, donde quizás recibieron la acogedora familiaridad de la casta Corvacho.

El drama de la guerra y sus repercusiones se extendieron en Arica por un período de 49 años (1880-1929), situando a la ciudad de Tacna y Arica en el centro del interés nacional y mundial, por su condición de indefinición respecto de su soberanía nacional chilena o peruana, y la expectativa de sus comunidades ante un plebiscito que finalmente nunca llegaría, siendo zanjado salomónicamente en 1929.

Esta situación afectó directa y dolorosamente la vida de Manuel, quien ya viudo desde 1916 se había concentrado en la prosperidad de su negocio. El primer golpe producto de este ambiente llegó tres años luego de su viudez, cuando su hija María fuera expulsada al Perú junto con su esposo Pedro, hijo de su entrañable amigo Domingo Pescetto, como resultado de las políticas de hostigamiento impulsadas por los dispositivos estatales y población chilena contra plebiscitarios peruanos, de los que Domingo, Pedro y María erran férreos militantes.

Pedro Pescetto y María Yanulaque vivieron el destierro en Lima y Moquegua desde donde observaban el desarrollo del complicado conflicto tacneño-ariqueño a la distancia, pero muy conscientes e informados de su pulso local ${ }^{11}$. 


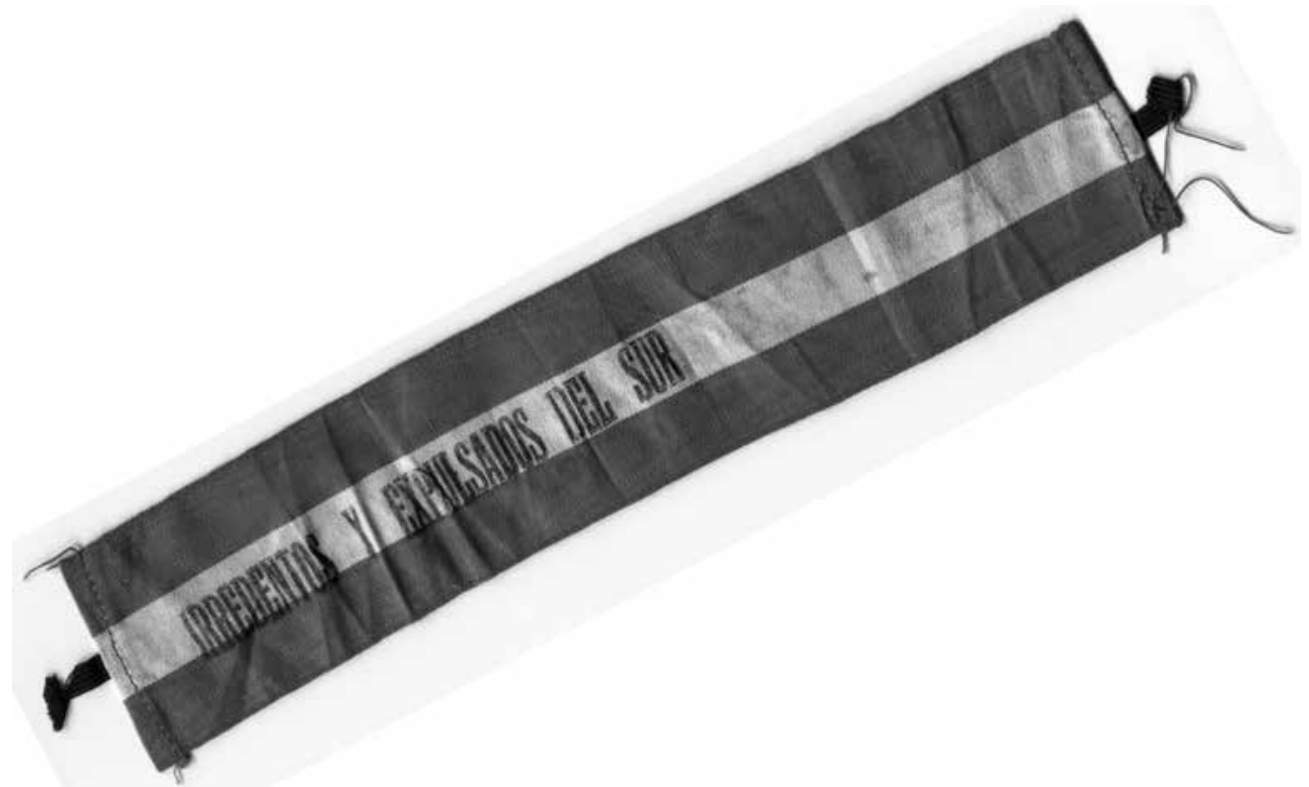

“Irredentos y expulsados del sur”, brazalete con el que Pedro Pescetto se identificó como peruano-ariqueño durante su exilio en Lima.

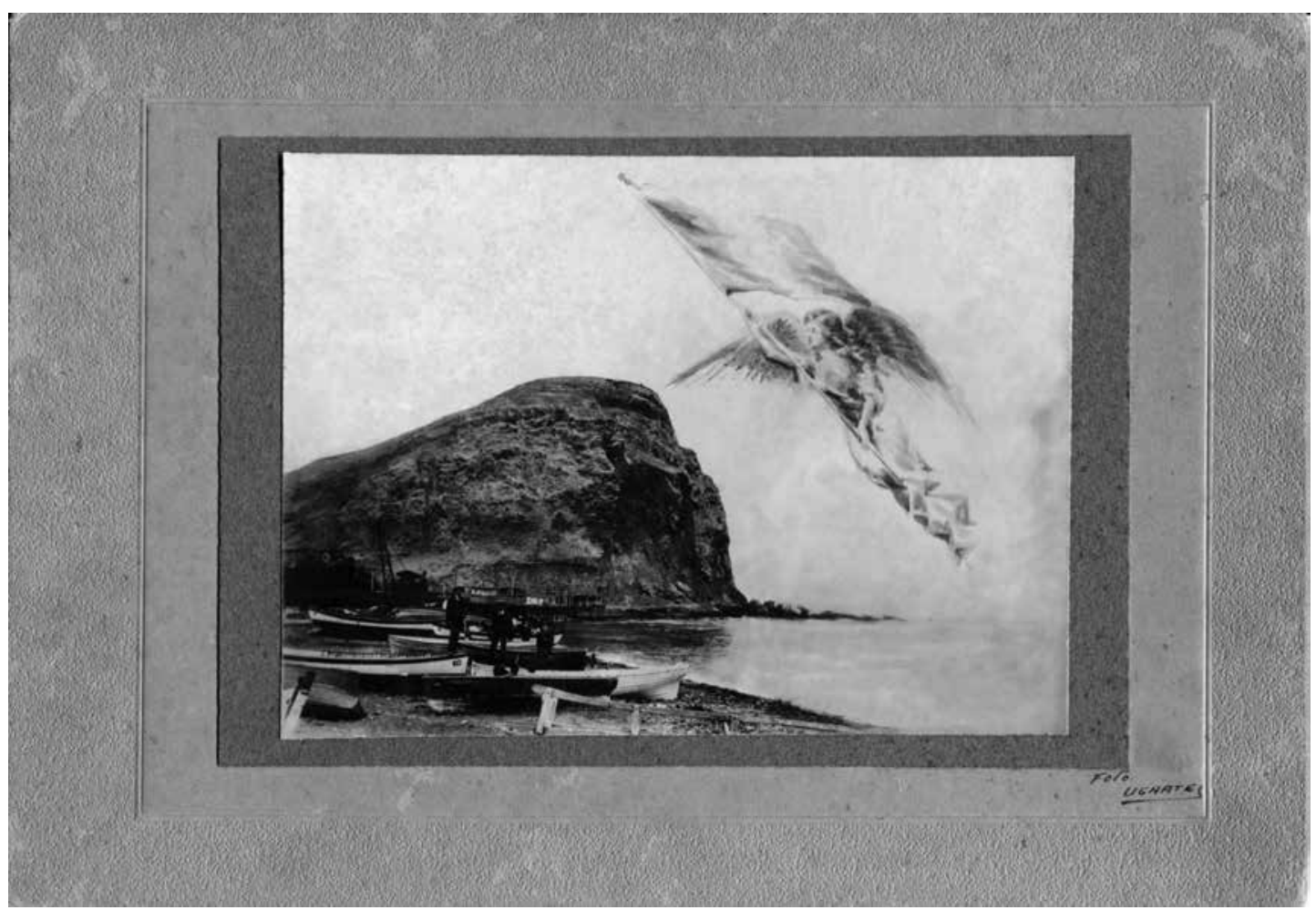

Postal alegórica y evocadora peruana sobre el morro. Postal alegórica y evocadora del Arica peruana perteneciente a Pedro Pescetto y María Yanulaque en el exilio. FMY326. 
A este primer golpe se sumó luego el autoexilio de su hijo mayor José, en 1926, quien decidió optar por el doloroso autoextrañamiento a partir de los crueles acosos antiperuanos, siendo recordado el episodio del asalto y destrucción parcial del "Teatro Nacional" de su propiedad, hecho traumático que impulsó su partida a Lima (Bresciani 2013). Años más tarde se sumaría a José su hermano Leónidas, un tercer golpe.

Con su familia disgregada producto del drama de la posguerra, los últimos años de Manuel estuvieron marcados por este dolor, no obstante y con un espíritu fuerte distinto al abatimiento, Manuel administró los bienes de los familiares y de sus amigos expulsados al Perú.

Al complicado escenario político y diplomático que determinó el fin de la década de 1920 se sumó la crisis económica mundial desatada en 1929, situación que afectó los negocios internacionales sostenidos por Manuel, en este período se provocó el descenso de los vínculos comerciales europeos, y un detrimento de la influencia en el área centro sur andina de "La Colmena", perdiendo sus vínculos con Arequipa y La Paz, por lo que esta se volcó al abastecimiento local, giro que mantuvo hasta el momento de su cierre en la década de 1980.

A pesar de que las dificultades que presentaba el comienzo de la década de 1930, el nuevo decenio trajo consigo grandes alegrías personales para el viejo Manuel, ya que la firma del tratado de 1929 puso fin -en el papel- al acoso antiperuano reinante en Arica y Tacna; de modo tal que volvieron a Arica los exiliados en los duros tiempos del plebiscito.

Manuel vio en 1931 el retorno de su hija María y Pedro, así como el de su hijo José que luego de emprender aventuras en el altiplano chileno administrando la pulpería de las azufreras de Tacora y Aguas Calientes se asentó en la vieja casona junto a su padre. Misma suerte siguió su tercer hijo que vivió el extrañamiento, Leónidas.

En sus últimos años de vida, Manuel estuvo al cuidado de sus hijas Bárbara y Catalina, quienes se habían nacionalizado chilenas para mantenerse en Arica junto a su viejo padre durante el complejo período plebiscitario para atender las necesidades de un Manuel ya anciano.

Producto de diversas enfermedades, Manuel Yanulaque fallece un día 24 de octubre de 1934, rodeado de sus familiares y amigos que masivamente los acompañaron en su último viaje.
El diario "El Ferrocarril" reflejó en su obituario del día 25 de octubre, el sentido pesar de la colonia griega residente en Arica, compuesta en ese entonces por las familias Miccos, Malliaras, Panagotis, Armenakis, Pachopulos, Maliakas, Sifaqui, Fergadiotis, Laloumis, Lazarou, Ligueros, Vadulli, Anastassiou, Pagonis, Nicolau y Vassiliadis, sentir también expresado por el Cónsul griego asentado en Valparaíso George Mustakis. Al fallecimiento de Manuel el siguiente relato resume su significancia para la comunidad local

"La Colonia griega residente en este puerto, se encuentra de duelo, con motivo del desaparecimiento del más prestigioso de sus miembros, don Manuel Yanulaque (QEPD). El señor Yanulaque fallece a una edad bastante avanzada, después de haber dedicado su inteligencia extraordinaria, su espíritu de empresa y sus energías inagotables, en fin toda su vida, al comercio. Así se explica que haya llegado a formarse una situación sólida, envidiable, muy difícil de alcanzar en un puerto pequeño, y su firma comercial considerada la más importante y de mayor seriedad en sus diversas y múltiples actividades.

Como hombre de empresa nunca rehuyó las tareas difíciles, mientras más sembrada de escollos la ruta, con mayor placer y entusiasmo luchaba. Esta cualidad tan importante en su carácter era su rasgo preponderante, a ella debió entonces sus grandes éxitos.

Padre de un hogar respetable formado actualmente por varios hijos que siguen la huella luminosa que les trazara en vida con el ejemplo.

Para los miembros de la colonia es una pérdida irreparable, ya que perdimos al compatriota más querido, al que acudíamos en los momentos más difíciles y de incertidumbre, en una palabra perdimos a nuestro Jefe, a nuestro patriarca.

Entre el comercio desaparece uno de sus miembros más conspicuos, una de sus figuras principales, uno de los hombres que siempre sirvió de ejemplo por sus raras virtudes. A su desconsolada familia nuestro más sincero pésame. FMYS. El Ferrocarril 25 de octubre de 1934. 


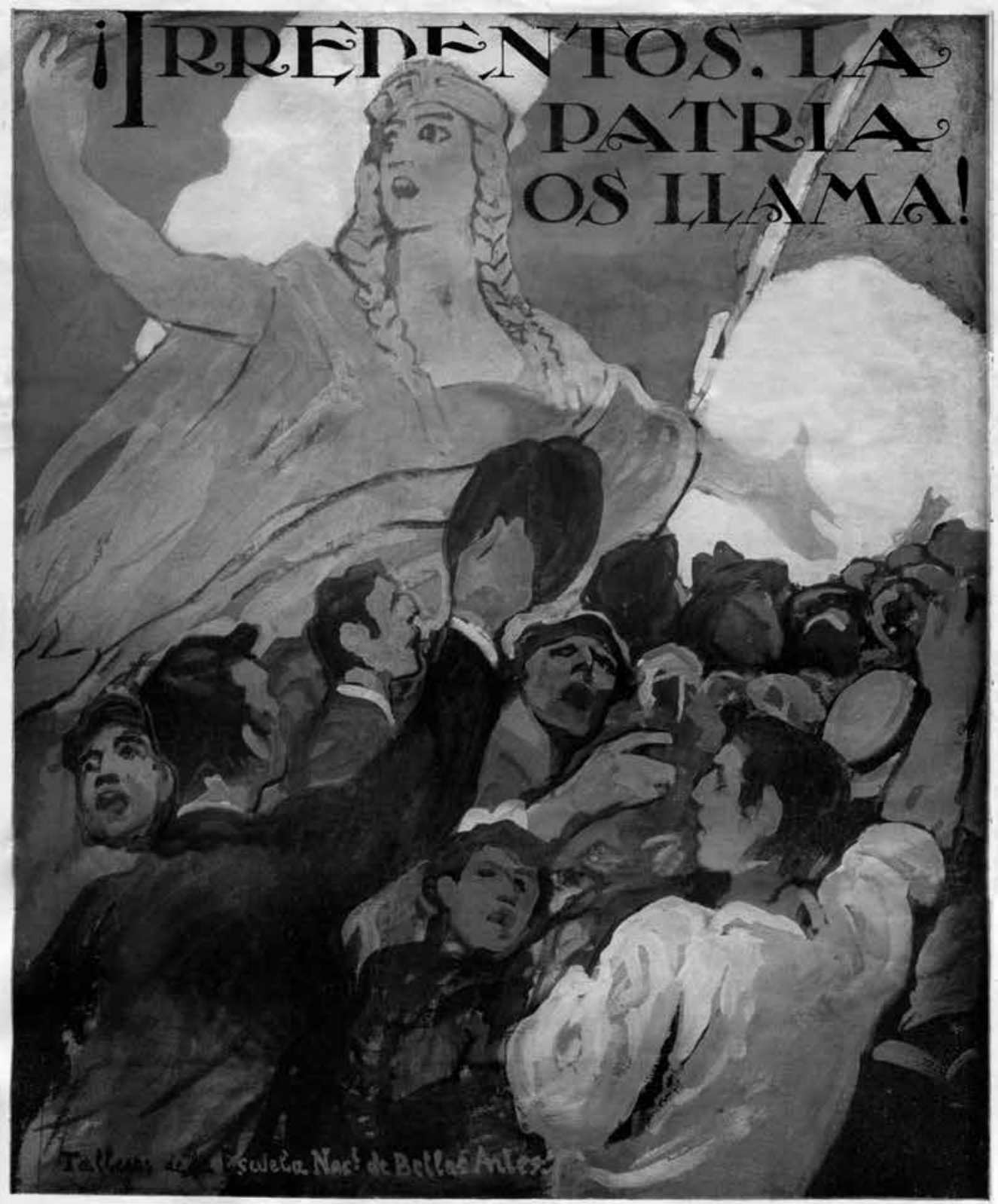

Afiche plebiscitario pro causa peruana perteneciente a Pedro Pescetto y María Yanulaque en su exilio. Documento que forma parte del archivo Yanulaque.

Pero todo esto, más que una lápida material que canta su mérito, vale el recuerdo imborrable que cada compatriota conservará en su corazón, de este hombre activo y bueno".

La despedida del viejo patriarca fue muy concurrida, discurseada y dolida, su sepelio alteró el diario vivir de los ariqueños el otoño de 1934 , momento en que la aventura del joven griego que 84 años antes se embarcara en la isla de Paros con rumbo incierto, terminó.

Sus restos descansan hoy en el mausoleo Yanulaque del Cementerio Municipal de Arica. 


\section{Comentarios finales}

La existencia de registros de una experiencia vital, de una trayectoria inmigrante y su consecuente proceso de asimilación en una cultura local -que incluye el involucramiento activo o pasivo en conflictos nacionales y políticos- constituye un privilegio en cuanto al obtener "llaves" o claves para entender procesos globales y con profundidad histórica que fragmentadamente no adquieren una visibilidad adecuada.

En la figura de Manuel Yanulaque -siguiendo una clave weberiana-se reconoce una representación de un tipo-ideal en cuanto que a partir de su historia y registro se puede acceder a las características del mundo inmigrante, sus dramas, éxitos y derrotas en el tránsito del siglo XIX al XX sudamericano.

Sin embargo, dicha conclusión independiente de su validez oculta los elementos más atractivos en cuanto a cualidad y profundidad de análisis a partir de sus características. La vida de Manuel refleja el transitar de un europeo por una sociedad multicultural y multiétnica, evidenciando las aperturas de la sociedad ariqueña y europea hacia el pluralismo durante el siglo XIX. Características que obedece a una era y pulso que tal vez ya no existe.
A su vez, el éxito económico de un inmigrante en una comunidad marginal del sur peruano como lo era Arica en relación con otras, refleja el ímpetu, capacidad, oportunidad, esfuerzos adicionales y alianzas que debió enfrentar no solo Manuel, sino que una gran parte de la comunidad forastera existente en Arica hacia la segunda mitad del siglo $\mathrm{XX}$. Del registro Yanulaque y su trayectoria es posible evaluar el rol jugado por algunos personajes extranjeros dentro de las comunidades receptoras en cuanto al desarrollo económico y social.

Sin duda, uno de los elementos más complejos en la biografía de Manuel lo entrega su experiencia y rol en torno a los complejos procesos sociopolíticos vividos en la región de Arica posguerrra del Pacífico, considerando que los demás elementos señalados responden a situaciones comunes y observables en cualquier parte del mundo.

La figura de Manuel Yanulaque en un período de convulsión política se ennaltece al momento de evaluar una postura equilibrada, mesurada y diplomática, que si bien puede explicarse por la distancia observadora otorgada por su origen griego que mantuvo hasta el final de sus días, se matiza y fortalece considerando el dolor que provocó el hecho de que su núcleo familiar haya sido parte

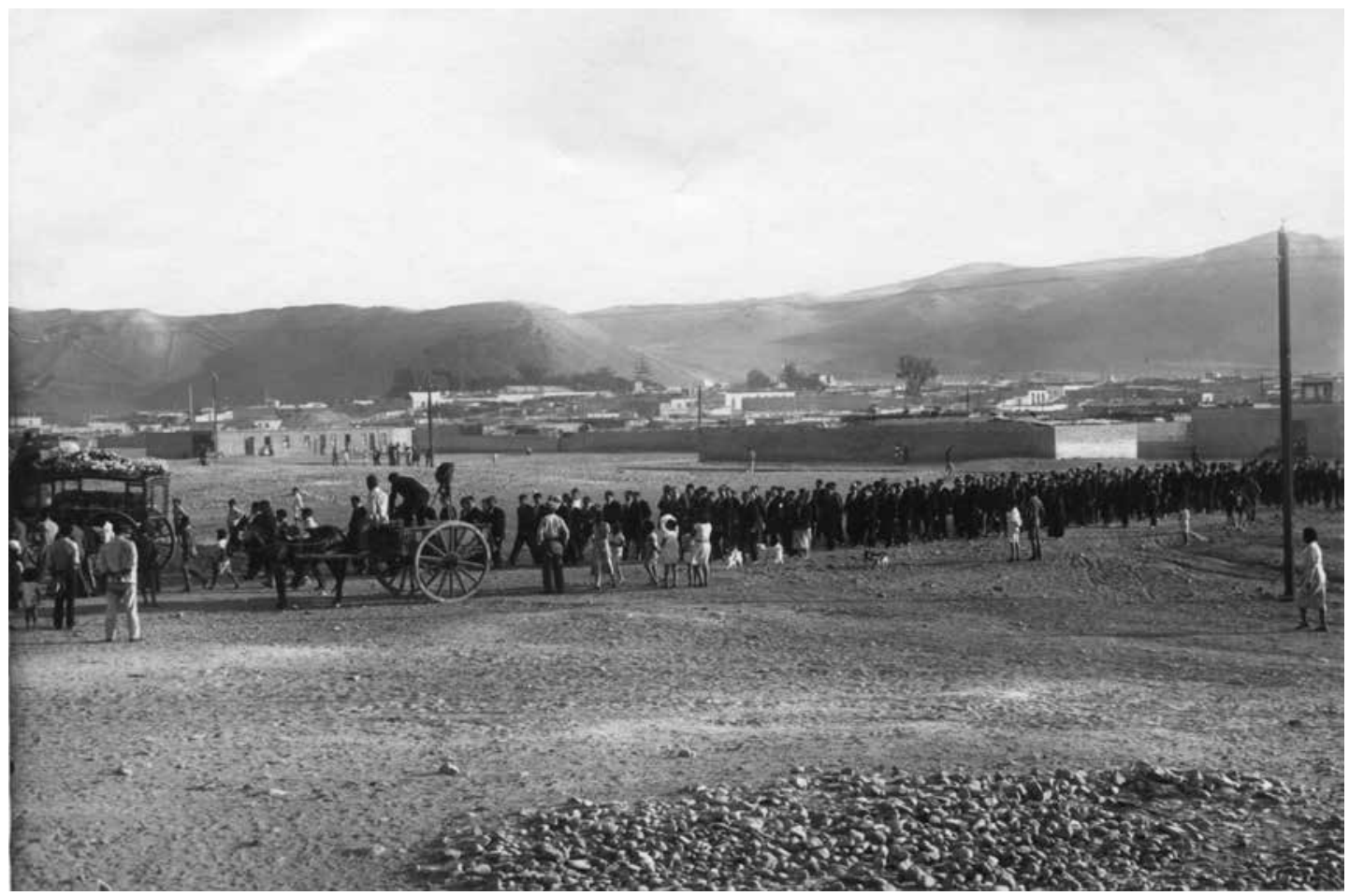

1934. Sepelio de Manuel Yanulaque. 
activa y militante de los bandos en disputa. Dicha mesura, calculada u honesta, representa desde una óptica generalizadora un rol o papel preponderante en cuanto a la articulación de los procesos de transición posconflicto bélico, en donde hombres de la talla de Manuel sirvieron como articuladores de una sociedad desgarrada por el drama de la guerra y sus posteriores calamidades.
Sumariamente, el caso de Manuel Yanulaque, así como muchos otros no documentados o subrepresentados, pone en relieve una necesidad que desde la inducción generalizadora y cualitativa, se maticen los macroprocesos locales, apelando al complemento entre la singularidad y la visión estructural de larga duración.

\section{Referencias Citadas}

Benjamin, Walter

2010 [1936/1952] El narrador. Traducción de Pablo Oyarzún. Metales pesados. Chile.

Bresani, Raúl

2013 La Casa Yanulaque en Arica: Homenaje a un peruano. Boletín Institucional Benemérita Sociedad de Auxilios Mutuos de Señoras de Tacna $N^{\circ}$ 5: 6-7.

Burke, Peter

2000 Formas de Historia Cultural. Alianza Editorial. España. 2005 Visto y no visto. El uso de la imagen como discurso histórico. Crítica. España.

2006 ¿Qué es la historia cultural? Paidós. España.

Choque, Carlos

2012 Fortunato Manzano. El último Yatiri. Vida, ritualidad, enseñanzas y religiosidad en Arica y Parinacota. Corporación Nacional de Desarrollo Indígena. Chile.

Díaz, Alberto, Rodrigo Ruz, Luis Galdames y Alejandro Tapia. 2012 El Arica peruano de ayer. Siglo XIX. En Atenea № 505: 159-184.

Díaz, Alberto, Rodrigo Ruz, Luis Galdames

2013 En los intersticios de la chilenidad. Antonio Mollo y las identidades en conflicto en los Andes. Putre 1900-1926. En Chungara, Revista de Antropología Chilena Volumen 45, $\mathrm{N}^{\circ}$ 3: 473-492.

Díaz, Alfonso

2000 Presencia italiana en la ciudad de Arica: 1885-1950, Ediciones Universidad de Tarapacá, Chile.

2002 Apuntes sobre los italianos en la provincia de Tarapacá (1870-1950). En Amérique Latine Histoire et Mémorie, Les Cahiers ALHIM No 5, [En línea], puesto en línea el 23 junio 2006. URL : http://alhim.revues.org/715. Consultado el 4 octubre 2013
Doose, François

2007 El arte de la biografía. Entre historia y ficción. Universidad Iberoamericana. México.

Galdames, Luis

2013 Presentación. En Archivo Fotográfico. Manuel Yanulaque Scorda (1850-1934). Historia e imágenes ariqueñas. Ediciones Universidad de Tarapacá/Consejo Nacional de las Artes y la Cultura. Chile.

1999 El ámbito de lo local como perspectiva de análisis de los pueblos andinos del norte de Chile. En Diálogo Andino $\mathrm{N}^{\circ}$ 18: 9-19.

Galdames, Luis, Rodrigo Ruz y Alberto Díaz

2008 Arica y sus valles en el siglo XIX. Estudio del censo de 1866. Ediciones Universidad de Tarapacá. Chile.

Hernández, Elena

2004 Tendencias historiográficas actuales. Escribir historia hoy. AKAL. España.

Noiriel Gérard

1996 Sobre la crisis de la Historia. Ediciones Cátedra. España.

Ruz, Rodrigo y Ariela González

2013 Archivo Fotográfico. Manuel Yanulaque Scorda (18501934). Historia e imágenes ariqueñas. Ediciones Universidad de Tarapacá/Consejo Nacional de las Artes y la Cultura. Chile.

Ruz, Rodrigo, Alberto Díaz y Luis Galdames

2008 Población andina de las provincias de Arica y Tarapacá. El censo inédito de 1866. Ediciones Universidad de Tarapacá Chile.

Serna, Justo Serna y Ancalet Pons

2000 Cómo se escribe la microhistoria. Ediciones Cátedra. España.

2013 [2005] La Historia Cultural. Autores, obras, lugares. AKAL. España.

\section{Notas}

1 Entendiéndola en su acepción más amplia, en su diversidad de soportes, sean intangibles o tangibles.

2 Situación que erróneamente justificó durante años la ausencia de investigación regional, especialmente en torno a la situación indígena y de otros grupos humanos y sociales no estudiados bajo el argumento de la existencia de "silencios documentales" o escasa representación en archivos. Situación que con el paso del tiempo y el desarrollo de programas de investigación regional ha ido siendo revertida (Galdames 1999, 2013).
Uno de los más conocidos pasajes de El Narrador (1936) del profusamente citado filósofo alemán Walter Benjamin, en la traducción e indización realizada por Pablo Oyarzún (2010 [2008]) refiere al trauma resultante de la experiencia brutal obtenida de los desastres humanitarios como la guerra, ejemplo y simple detalle que a pesar de las dudas, nos inspira al momento para abordar temáticas locales conscientes del conflictivo pasado regional en que nos desenvolvemos. La referencia nos señala que "Con la Guerra Mundial comenzó a hacerse evidente un proceso que desde entonces no ha 
llegado a detenerse. ¿No se advirtió que la gente volvía enmudecida del campo de batalla? No más rica, sino más pobre en experiencia comunicable" (Benjamin 2010: 60. Traducción de Pablo Oyarzún).

4 Fondo Manuel Yanulaque Scorda [FMYS] (1850-1934). Bajo custodia del Archivo Histórico Vicente Dagnino [AHVD] dependiente del Departamento de Ciencias Históricas y Geográficas de la Universidad de Tarapacá.

5 Haciéndose cada vez más común encontrarse con corrientes historiográficas que apelan al desarrollo de las sensibilidades, afectos y otros aspectos inefables de la vida, su cultura y humanidad.

6 Notables en su desarrollo y fineza, son los trabajos nuevo cuño, orientación e incluso nueva epistemología desarrollada en pro de lograr una cercanía con su sujeto de estudio emprendidos desde una perspectiva emic reflejado por Choque (2012), mientras que en el plano disciplinar histórico, que recoge la extensa tradición proveniente de los estudios andinos (entendidos como el vínculo disciplinar antropológico e histórico) en Díaz et. al. (2013).
7 AHVD. Volumen 343

8 Relato que se complementa con el dato oral familiar que señalaba que Manuel habría vivido el terremoto y maremoto de 1877.

9 Registros censales levantados años antes de la fecha de desembarco de Yanulaque en Arica (1866) arrojan que la población urbana ariqueña ascendía a 2.846 habitantes, mientras que en sus valles y espacios precordilleranos y altiplánicos concentraban a 5.170 personas.

101.514 ariqueños netos, nacidos en la provincia de Arica, a los que se suman 669 personas provenientes de otras provincias peruanas, 295 bolivianos, 186 europeos, 21 asiáticos, 21 sudamericanos, 4 americanos del norte y 16 indeterminados.

11 Objetos personales de Pedro a su retorno a la Arica ya chilena en 1931, hablan de sus anhelos en el extrañamiento. Pedro atesoró durante años los ejemplares del famoso pasquín peruano nacionalista "La voz del sur" así como otros objetos testimonios de su destierro expuestos en esta publicación, materiales que permanecieron resguardados en la casa de Manuel. 
